\title{
CINEMA E LITERATURA NA ESCOLA COMO INCENTIVO À FORMAÇÃO DE LEITORES'
}

\author{
MOVIES AND LITERATURE IN SCHOOLS AS A \\ MOTIVATION TO FORM READERS
}

\section{Denise Stefanoni Combinato ${ }^{2}$ Claudete Moreno Ghiraldelo 3}

1 Apoio: Fundação de Amparo à Pesquisa do Estado de São Paulo (FAPESP) e Conselho Nacional de Pesquisa (CNPq).

2 Doutora em Saúde Coletiva (UNESP/Botucatu), Graduada em Psicologia (UNESP/Bauru). Professora colaboradora do Departamento de Humanidades, Instituto Tecnológico de Aeronáutica (ITA). E-mail: denisecombinato@hotmail.com

3 Doutora em Linguística Aplicada (UNICAMP), Graduada em Letras (UNESP/Araraquara). Professora aposentada do Departamento de Humanidades, Instituto Tecnológico de Aeronáutica (ITA). Professora do curso de Pós-graduação lato sensu “Psicanálise: teoria e técnica”, Universidade do Vale do Paraíba (UNIVAP). E-mail: clau.cmg@gmail.com 
RESUMO: O objetivo deste artigo é apresentar uma reflexão sobre o trabalho junto a estudantes do Ensino Médio com cinema de autor e literatura, diferenciando essas produções daquelas feitas pela indústria cultural, que seriam as produções de grandes estúdios cinematográficos e as de livros de literatura de massa. Essa reflexão baseia-se na experiência com projetos de pesquisa e de extensão junto a professores e estudantes de três escolas estaduais em São José dos Campos, São Paulo.

PALAVRAS-CHAVE: Cinema de autor; Literatura; Ensino Médio; Leitura de textos e imagens; Escola pública.

ABSTRACT: The aim of this article is to present a reflection on the work about the author of movies and literature, which was done with High School students and that distinguing these productions from those of cultural industry, namely the productions of big movies studios and those of mass literature. This reflection is based on the experience with research and extension projects with teachers and students of three state schools in São José dos Campos, São Paulo.

KEY-WORDS: Author movies; Literature; High School; Reading of texts and images. Public school. 


\section{INTRODUÇÃO}

O teatro para crianças deve ser igual ao dos adultos, só que melhor.

Stanislavsky

Há um discurso corrente nos espaços educacionais brasileiros, segundo o qual a escola deve ensinar a partir do universo cultural dos estudantes e a aprendizagem deve ser prazerosa.

Esse discurso, que vem de longe, foi bastante disseminado após a democratização do ensino público, a partir dos anos 1960, e sobretudo nos anos 1970 e 1980 com a reformulação dos currículos, visando minimizar ou extinguir a repetência e a evasão escolar. São diversos os documentos e publicações de Secretarias de Educação de Estados, dirigidos a professores, calcados em teorias da aprendizagem especialmente piagetianas, o construtivismo, apresentando e insistindo que o papel do professor é de mediador, daquele que facilitaria a aprendizagem do aluno e a aprendizagem deveria sempre partir do conhecimento e universo cultural do aluno. A proposta é de que isso ocorra como ponto de partida e, pouco a pouco, se ultrapasse o conhecimento do aluno e avance no que é estabelecido como conhecimento de cultura nacional e universal. Cabe uma pergunta, será que todos os alunos têm tido essa oportunidade de acessar a cultural nacional e universal?

O que se percebe com o "aprender a aprender" ${ }^{4}$ slogan exaltado pelo construtivismo - talvez se aproxime mais de uma expropriação do saber, na lógica da edu-

4 O “aprender a aprender" pode ser sintetizado em quatro posicionamentos valorativos: 1) o conhecimento construído sozinho pelo aluno é mais importante que o conhecimento obtido através da mediação do professor, pela socialização do conhecimento na escola; 2) o método ou a competência para buscar o conhecimento é mais importante que o conhecimento já existente e consolidado na sociedade; 3) a busca do conhecimento deve ser orientada espontaneamente pelos interesses e pela prática cotidiana dos alunos e não pela escola e professores; 4) os indivíduos devem ser formados para se adaptarem rapidamente à sociedade e ao mercado de trabalho e não para questionarem o modelo produtivo e buscarem projetos coletivos de transformação da sociedade. Ou seja, há uma desvalorização do ato de ensinar e do conhecimento acumulado historicamente, um esvaziamento do papel da escola e do professor (DUARTE, 2001). 
cação neoliberal. Quanto menos conhecimento, mais facilmente adaptado é o indivíduo, menor resistência oferece ao sistema político-econômico, menor articulação estabelece com seus pares e maior adesão e defesa ao modelo produtivo existente se opera, como se fosse único e natural.

De acordo com Laval (2019),

O saber não é mais um bem que se adquire para fazer parte de uma essência universal do humano, como no antigo modelo escolar - que, diga-se de passagem, reservava esse bem supremo a poucos -, mas um investimento mais ou menos rentável para indivíduos com dotes materiais e intelectuais desiguais. Os valores que constituíam o mundo escolar foram substituídos por novos critérios operacionais: eficiência, mobilidade, interesse (p.48).

O que vem ocorrendo é que a escola tem ficado em grande parte presa ao universo cultural do aluno, cujo acesso à cultura é basicamente a produzida pela chamada "indústria cultural", especialmente em relação a cinema (ou audiovisual) e música, e não salta para formas mais elaboradas de produção artística.

No campo da literatura brasileira, talvez justamente por haver conteúdos estabelecidos pelo Estado é mais difícil escapar a ele, mas isso não significa que eventualmente não sejam utilizadas ou recomendadas publicações que fogem ao escopo do que seria, de fato, a boa literatura. Nossa crítica de que a escola trabalhe demais tais produções da indústria cultural funda-se na concepção de que a escola deve ser um espaço por excelência onde o estudante possa ter acesso àquilo que desconhece, que não tem contato no seu cotidiano, produções que fazem parte de um "acervo" cultural da humanidade, seja do passado ou de hoje, e que nem sempre são de fácil acesso.

$\mathrm{Na}$ área do cinema, não é raro nos depararmos com a exibição de filmes comerciais, especialmente os hollywoodianos, os de mais fácil acesso, em salas de aula ou a recomendação por professores a alunos como atividade extraclasse. Assim, como na área musical não é raro festas escolares serem animadas predominantemente com músicas do cotidiano dos estudantes, tais como funk, sertanejo, dentre outros gêneros. Tais escolhas são prontamente justificadas por diversos professores de serem os tipos 
de filmes e de música que os estudantes mais apreciam. É de nos interrogarmos se, de fato, "apreciam" ou apreciam porque desconhecem outras produções.

Não se trata, evidentemente, de desconsiderar as produções da indústria cultural, nem mesmo de não poder se valer delas em alguns momentos do desenvolvimento curricular; torna-se um problema quando essas produções passam a predominar, ou em alguns casos a imperar, na escola. E isso ocorre principalmente, mas não só, nas escolas públicas.

Posto isso, o objetivo deste texto é promover uma discussão de como o cinema de autor e a literatura - e não o cinema e a literatura, produtos da indústria cultural - podem incentivar a formação de leitores - leitores de palavras, imagens e mundo, como diria Paulo Freire.

Tal discussão estará fundamentada em nossos estudos e experiências como coordenadoras de três projetos de pesquisa e extensão junto a estudantes e professores do Ensino Médio e da Educação de Jovens e Adultos, de escolas públicas, dois desenvolvidos individualmente com financiamento da FAPESP e um outro, desenvolvido conjuntamente, com a participação de alunos de graduação com bolsas de iniciação científica do CNPq/PIBIC 5 .

Este texto se divide em duas seções, além desta "Introdução" e das "Considerações finais". Na primeira, "Cinema de autor e literatura versus cinema espetáculo e literatura de massa", será feita uma discussão sobre o que se entende por "cinema de autor" e literatura e por que nos valermos desse tipo de arte na escola e não outro; na outra seção, "Cinema de autor e literatura na formação de leitores", discutiremos mais especificamente como a escola pode incentivar a formação de leitores através desse tipo de arte.

5 Os projetos de pesquisa são "Cinema e escrita (de si) - experiências com a escrita de alunos do Ensino Médio” (FAPESP, Processo n. 2011/51271-9), “Nós e os nossos nós: impactos da articulação entre literatura e audiovisual para o processo ensino-aprendizagem no Ensino Médio" (FAPESP, Processo n. 2014/50841-4) e "A tecnologia do cinema na construção da educação e da cidadania" (CNPq/PIBIC). 


\section{CINEMA DE AUTOR E LITERATURA VERSUS CINEMA ESPETÁCULO E LITERATURA DE MASSA}

A epígrafe que abre este texto, de Stanislavski ${ }^{6}$, foi por ele dito em uma época, século XIX, quando a criação da infância já havia vingado e ganhava força, época em que houve um debate sobre se as produções literárias para crianças deveriam ser as mesmas produzidas para leitores e espectadores adultos, ou se deveriam ser produzidas exclusivamente para o leitor e espectador infantil. Tomamos emprestada essa frase para uma analogia com outras produções culturais e outro público, estudantes de estratos econômico-sociais mais baixos, frase que assim ficaria: a arte (o cinema e a literatura, especificamente) para os estudantes de escola pública deve ser igual à dos mais ricos, de escolas privadas, só que melhor. Essa analogia com a frase de Stanislavski é também para marcar uma oposição a um discurso corrente e forte no Brasil, segundo o qual "para as pessoas pobres, qualquer coisa serve”, o que resulta em práticas desde a oferta de atividades culturais - em cidades onde há -, até a baixa qualidade das construções de escolas em bairros periféricos, de casas populares e assim segue.

Embora tomemos essa posição em relação à escola pública e à privada, sabemos que não há garantia alguma de que um estudante de escola privada tenha acesso ao cinema sem ser o comercial - cinema de autor - e aprenda a apreciá-lo. Não foram raras as ocasiões quando estudantes de cursos superiores declararam que se esse tipo de filmes não fosse a eles apresentado como partes de disciplinas, eles dificilmente buscariam para assistir, além de diversos deles dizerem que se não fossem suas escolas de Ensino Médio levarem-nos em excursões para conhecer museus de suas cidades, eles não teriam conhecido, mesmo fazendo parte de uma elite econômica e cultural e tendo pais com nível superior. Estudantes filhos de médicos, e outros profissionais que, em geral e a priori, estão nos estratos econômicos mais altos do país, residindo na cidade de São Paulo, declararam que só conheceram o MASP (Museu de Arte de São Paulo), porque suas escolas fizeram excursões para levá-los. É preciso considerar, no entanto, que es-

6 Constantin Sergeevich Alexeiev, mais conhecido por Constantin Stanislavski, (17/01/1863 - Moscou, Império Russo; 07/08/1938 - Moscou, União Soviética), foi ator, pedagogo e escritor. 
tudantes de redes privadas de ensino têm, em geral, maior acesso a bens culturais, tais como cinema, teatro, literatura, assim como a passeios e viagens, o que não ocorre com estudantes de escolas públicas, na sua maioria. Se os estudantes de estratos econômicos mais altos usufruem de tais possibilidades e quais são suas escolhas é uma outra questão que foge ao escopo deste artigo, o fato é que, ou mais ou menos, há o acesso.

Hoje é certo que o cinema faz parte do dia a dia dos jovens. Em um levantamento de 2012, junto a 154 estudantes do Ensino Médio, entre 15 e 18 anos, de uma escola pública e periférica de uma cidade do interior de São Paulo, quatro deles apenas disseram não se interessarem muito por cinema e, ainda assim, declararam assistir a pelo menos um filme por semana. Os demais disseram assistir de três a quatro filmes por semana e alguns, diariamente. A maior parte desses estudantes afirmaram assistir aos filmes em TV aberta, ou pelo celular, pela rede social YouTube; menos de $20 \%$ apenas tinham computador em casa ou acesso à TV por assinatura, duas outras formas de assistirem aos filmes; menos de $10 \%$ declararam ir pelo menos uma vez por mês ao cinema, havia ainda casos de alunos que nunca assistiram a um filme no cinema. Cabe um parêntese, aqui, para enfatizar que são dados de 2012, coletados junto a estudantes de uma escola de um bairro rural distante a aproximadamente $15 \mathrm{~km}$ do cinema mais próximo e com meio de transporte público com horários espaçados ao longo do dia. Essa relação com as produções cinematográficas dos jovens de hoje é muito diferente da relação de espectadores de gerações passadas. Um rápido levantamento na mesma época junto a 10 pessoas nascidas nas décadas de 1930 e 1940, em 2012, na faixa de 70 a 80 anos, metade delas com nível superior e metade com nível médio técnico, que vivem desde seus 20, 25 anos em cidades com pelo menos 500 mil habitantes, apenas duas delas declararam que assistiam pelo menos a um filme por semana ou a cada 15 dias; as outras pessoas disseram que assistiam a filmes eventualmente e, em geral, por TV por assinatura ou aberta, ou no cinema; declararam ainda nunca terem assistido a um filme pelo computador ou celular. Destaco, aqui, também que tais dados são de 2012, antes de plataformas de filmes e séries de televisão via streaming se popularizarem no Brasil ${ }^{7}$ (GHIRALDELO, 2016).

7 A Netflix, a provedora global de filmes e séries de televisão via streaming com maior número de assinantes, chegou ao Brasil em setembro de 2011. 
Considerando o fato de as produções cinematográficas estarem tão próximas do cotidiano desses estudantes, ocorre nos interrogarmos sobre que tipos de filmes esses jovens assistem, e, como era previsível, o que predomina são os filmes produzidos pelos grandes estúdios, os hollywoodianos, principalmente por serem de fácil acesso, já que são em maior número anualmente e os mais exibidos nas redes de televisão, assim como, segundo os estudantes, são mais compreensíveis e divertidos.

Esses filmes comerciais fazem parte do que é denominado pelos estudiosos da área de cinema de "cinema espetáculo" (GEADA, 1987), que são os produzidos pela indústria cultural, que produz a cultura de massa. São filmes cujos produtores e diretores almejam grandes bilheterias, pois anseiam como resultado altos rendimentos, são os que costumam ter lançamentos mundiais. Por mirarem o maior número possível de espectadores, procuram fazer suas produções tendo como norte um suposto "espectador médio", aquele imaginado pelos realizadores, que compreenderiam facilmente o enredo, assim como as imagens e os elementos estéticos (CHAUÍ, 2003).

Neste artigo, estamos usando como sinônimos os termos "cinema espetáculo", "cinema comercial" ou "cinema hollywoodiano" para designar o modo de funcionamento de tais produções cinematográficas, considerando ainda que foram os Estados Unidos que inauguraram as produções comerciais para grande público, tanto quando as produções se concentravam em Nova Iorque, no início do século XX, como quando, com o objetivo de baixar o custo de produção dos filmes, se transferiram para a Califórnia. Cabe reconhecer que o cinema espetáculo é produzido em diversos países, não exclusivamente pelas grandes produtoras de Hollywood, nos Estados Unidos.

A produção de filmes longas-metragens costuma ser de alto custo, além de envolver um grande número de profissionais. Embora quem ganhe a assinatura da obra seja apenas o diretor e, além deste, comumente têm destaque apenas atores e atrizes (em alguns casos podem se destacar o roteirista, o diretor de fotografia e o figurinista), o número de profissionais envolvidos em uma produção costuma ultrapassar facilmente dezenas ou centenas deles, conforme o filme, considerando desde os técnicos (de eletricidade, eletrônica, computação etc.) até os diretores de arte (iluminação, cenário, figurino etc.). Justamente por ser uma produção cultural cara e envolver o trabalho de muitas mãos, evidentemente que qualquer produção anseia 
por espectadores e por retorno financeiro. A diferença é que os filmes hollywoodianos já são produzidos com esse fim, chegando em alguns casos a terem um retorno de dez vezes ou mais o valor investido para a produção. Já as produções que sustentam autoria não costumam ter rendimentos tão vultosos.

Voltando um pouco na história do cinema, o conceito de "cinema de autor" começa a ser esboçado nos anos 1940 na França, por meio de publicações tanto de críticos e estudiosos de cinema, como dos próprios cineastas, no célebre periódico dedicado ao cinema, Cahiers du cinema, como de seções de jornais sobre cinema e cultura em geral. Cinema de autor, ou cinema autoral, são as produções em que o diretor de cinema, o cineasta, se vale da câmera como meio de expressão pessoal, ainda que a produção de um filme seja um trabalho coletivo, ele teria a assinatura do autor. Assim, o filme traz marcas, desde o tema, roteiro até posição de câmera, iluminação, cortes e tomadas de cenas que marcam a autoria do diretor, marca seu estilo.

Como bem destaca Rosenfeld (2009[1951]), os estúdios hollywoodianos produzem muitas dezenas de filmes anualmente, o que permite que deles apareçam grandes diretores, como é o caso de Martin Scorsese, Woody Allen, Francis Ford Coppola, só para nos atermos em alguns cineastas vivos que produzem há décadas. Mesmo esses grandes cineastas, no entanto, já mencionaram em entrevistas a dificuldade de produzir filmes autorais financiados pelos grandes estúdios, pois é comum os produtores - os que financiam a realização de um filme - interferirem, ou tentarem interferir, na criação, considerando o retorno financeiro que poderá ou não gerar. Não se pode ignorar ainda que o cinema hollywoodiano desenvolve técnicas inovadoras, que são lançadas ao mundo do cinema, além de que, devido à sua grande produção, aparecerem ocasionalmente bons filmes, comparáveis aos do cinema de autor.

Nos Estados Unidos também se produz filmes de autor, evidentemente. Há, inclusive, o anual Festival Sundance de Cinema, criado para impulsionar e fortalecer novos talentos no cinema de autor. É preciso também reconhecer que nem todo filme de autor tem qualidades de conteúdo e estéticas.

Assim, uma marca substancial entre os filmes comerciais e os de autor diz respeito às condições de produção, à motivação para a realização de um filme, se o mais 
importante é o retorno financeiro ou, sem desprezar esse aspecto, a possibilidade de um cineasta, tal como um artista, poder imprimir sua assinatura na produção.

Os aspectos mais marcantes entre as produções hollywoodianas e as de autor, que costumam ser mencionados pelos espectadores acostumados aos filmes comerciais quando assistem a um filme de autor, respectivamente são: ritmo acelerado versus ritmo lento; trilha sonora obrigatória $v s$. trilha sonora opcional; explicitação de elementos da história em cenas e diálogos entre os personagens $v s$. nem tudo é explicitado; humor obrigatório independente do gênero do filme $v s$. humor opcional; final conclusivo $v s$. nem sempre há final conclusivo.

O ritmo acelerado do cinema espetáculo faz com que o filme todo tenha muita ação, movimento, aconteçam coisas, diferentemente dos filmes de autor, que podem ter longas tomadas de uma cena, longos silêncios. As produções comerciais costumam ter trilha sonora, como uma maneira de envolver o espectador e emocioná-lo, já o cinema de autor, quando bom, envolve pelo próprio enredo, desempenho dos artistas, elementos estéticos, como iluminação, tomada de cena, por exemplo. É comum também que as produções comerciais explicitem a história, as relações entre os personagens de maneira a facilitar a compreensão pelo espectador, o que nem sempre ocorre nos filmes autorais. Também é recorrente nos filmes comerciais ações e diálogos supostamente bem-humorados, como estratégia para cativar o espectador, o que nem sempre ocorre em filmes de autor, em alguns, inclusive, dependendo do cineasta e de seu país de origem, há poucos diálogos. Os filmes comerciais costumam apresentar finais conclusivos, explícitos, enquanto muitos filmes de autor apresentam finais que parecem uma suspensão da história, nada mais. Se tomamos essas características do cinema de autor, dá para traçar o trabalho mental do espectador para interpretar um filme. O ritmo lento da história possibilita vagar por diversos pensamentos enquanto se assiste ao filme; a ausência de trilha sonora poderá envolver o espectador não pela comoção, mas por emoções e sentimentos mais elaborados; os implícitos em um filme obrigará o espectador a pensar sobre o que assiste, conjecturar desencadeamentos da história, pois nem tudo é apresentado pronto; o humor de cenas e nos diálogos entre os personagens, que nem sempre está presente, pode levar o espectador a se ater nas capacidades de representação dos atores; um final nem sempre conclusivo e explícito 
pode levar o espectador a muitas especulações sobre o desfecho da história, ressignificando, inclusive, partes do filme desde seu início.

Os filmes com as características dos comerciais tornam-se repetitivos para o espectador, o que facilita a compreensão, mas, por outro lado, amortece os sentidos, não promove a reflexão mais profunda de temas variados, bem como de sentimentos e afetos. A cultura de massa é escapista, leva a uma fuga da realidade.

No âmbito da literatura de massa, como é chamada a literatura produzida tendo como norte a grande vendagem de livros, retorno financeiro, as características são semelhantes às do cinema comercial. As histórias costumam ter muita ação, muitos acontecimentos, os personagens, em geral, não são complexos - são personagens planas $^{8}$, como são denominadas na área de teoria literária -, os diálogos são explícitos entre os personagens e a linguagem é simplificada. São livros para entretenimento e, assim como o cinema comercial, também é pressuposto um leitor médio (CHAUÍ, 2003).

O enredo até pode ser inovador, mas a forma não ultrapassa o lugar-comum. Tudo para não exigir demais da atenção, do pensamento, da linguagem e da imaginação do leitor. Mantém-se a mesmice na produção literária para não provocar, não desestabilizar e não libertar o leitor da mesmice que é. Mantém-se, principalmente, o mercado.

Ricardo Azevedo, escritor e ilustrador, confirma que é a orientação do mercado que diferencia o ilustrador literário do ilustrador publicitário. Enquanto o ilustrador publicitário adere a uma linguagem considerada da moda por imposição do mercado, para o ilustrador literário, o que conta é "a questão da pessoalidade, da cultura visual, do desenvolvimento de uma linguagem autoral" (MORAES, HANNING, PARAGUASSU, 2012, p.95).

A descoberta através de personagens, diálogos, ambientes, símbolos, contrastes, ambiguidades e ironias pode ser prazerosa, mas é trabalhosa para o leitor, uma vez que confronta com suas histórias, seus valores, gostos, desejos, frustrações, dúvidas e repertório (PERISSÉ, 2006).

8 As personagens planas são aquelas que recebem um único atributo ou característica, permanecendo inalterada ao longo da narrativa. Já a personagem complexa ou redonda é aquela que surpreende pela capacidade de mudança ao longo da história (WOOD, 2011). 
A literatura rompe com a linguagem do cotidiano, cria novas imagens e possibilidades, promove a reflexão e a crítica do leitor: "A arte, e no caso a literatura, é para criar o desequilíbrio, buscar outro prumo, e não botar pano quente em inquietações mornas" (QUEIRÓS, 2012, p.80).

Entretanto, conforme criticava Saramago (2010), "estabeleceu-se e orientou-se uma tendência para a preguiça intelectual" (p.463).

Ao discutir sobre arte e “ideologia da velocidade”, Gonçalves Filho (2002) afirma que variadas produções literárias são feitas para "o aqui e o agora, prontas simplesmente para a fruição imediata, rápida" (p.96). Isso porque a rapidez presente na vida cotidiana é incompatível com o tempo exigido pela arte.

Mas isso tem consequência: podemos perder a capacidade de leitura - não de palavras e imagens isoladas -, mas da história humana.

A cultura, o sentido cultural, tem agora muito mais a ver com o espetáculo e menos com a cultura reflexiva, ponderada, que faz pensar. Tudo se converteu em espectáculo.

Todos os dias desaparecem espécies animais, vegetais, idiomas, ofícios. Os ricos são cada vez mais ricos e os pobres mais pobres. Cada dia há uma minoria que sabe mais e uma maioria que sabe menos. A ignorância está a expandir-se de forma aterradora. Temos um grave problema na redistribuição da riqueza. A exploração alcançou um requinte diabólico [...] Estamos a perder a capacidade crítica do que se passa no mundo [...] Estamos a abandonar a nossa responsabilidade de pensar, de agir (SARAMAGO, 2010, p.487).

Por isso, defendemos e atuamos para que a escola não abra mão do seu papel na formação crítica dos sujeitos, para que promova o acesso a obras de arte autorais, que incentive o trabalho do leitor/espectador - ainda que árduo -, oferecendo subsídios para que ele possa participar, interrogar e criar a partir da obra fílmica e literária. 


\section{CINEMA DE AUTOR E LITERATURA NA FORMAÇÃO DE LEITORES}

Nos projetos de pesquisa e extensão coordenados pelas autoras desse artigo foram exibidos e discutidos filmes autorais, assim como lidos e analisados textos literários com alunos de Ensino Médio e Educação de Jovens e Adultos de escolas públicas.

Mesmo algumas obras sendo nacionais ou vencedoras de vários prêmios, como é o caso de $O$ menino e o mundo, os alunos não tiveram acesso a elas fora da escola.

Vale ressaltar que foi homologada uma lei (Lei no. 13006/2014) que obriga as escolas de Educação Básica a exibirem filmes nacionais por, no mínimo, duas horas mensais (BRASIL, 2014). O conteúdo dessa lei integra o artigo no 26 da Lei de Diretrizes e Bases (LDB) da educação nacional (BRASIL, 1996).

Se, por um lado, essa lei poderia demonstrar alguma preocupação com o acesso ao cinema e, em particular, a valorização do cinema nacional na escola, por outro, não se verificou nenhum debate com a escola ou a regulamentação de condições estruturais e educativas para sua execução. Pelo contrário, nas escolas onde foram desenvolvidos esses projetos de pesquisa e extensão, por exemplo, professores e gestores desconheciam tal lei.

De acordo com o Censo da Educação Básica de 2019, existem 180 mil escolas no país. Em escolas de Ensino Fundamental, o projetor multimídia, equipamento básico para a exibição de filmes, está presente em apenas 52,9 \% das escolas municipais - que são a maioria nesse tipo de ensino -, 70,6\% das escolas privadas, 79,9\% das escolas estaduais e 91,5\% das escolas federais, que são minoria nesse tipo de ensino (MEC/INEP, 2020).

Além das condições estruturais, vale perguntar, quem é responsável pela seleção dos filmes? Como os filmes selecionados são obtidos para a exibição na escola? Os professores têm uma formação estética para a discussão das obras fílmicas? Há um momento para estudo e planejamento sistemático dos professores para o desenvolvimento dessas atividades com os alunos, já que a lei pressupõe a exibição mensal de filmes articulada à proposta pedagógica da escola? Ou, conforme questionam Fresquet e Paes (2016, p.165), “a proposta apenas visa aumentar os ganhos da indústria cinematográfica nacional, apostando no espaço da escola como 'novo' filão de mercado?" 
Selecionamos - e defendemos que a escola selecione - filmes e textos literários que ampliem a experiência de alunos e professores com o cinema e a literatura, indo além "do gosto consagrado pelo mercado" (NAPOLITANO, 2009, p.16-7), mas com a formação necessária e o tempo adequado para o planejamento, execução e avaliação dessas atividades pelos professores.

Após a exibição do curta Os fantásticos livros voadores do Sr. Morris Lessmore (JOYCE; OLDENBURG, 2011), alunos do $1^{\circ}$ ano do Ensino Médio de uma Escola Pública aplaudiram-no. Durante a exibição do longa O menino e o mundo (ABREU, 2014), uma animação, sem diálogos, alunos do $2^{\circ}$ ano do Ensino Médio “não piscavam", tamanha atenção. Olga (MONJARDIM, 2004), um longa que retrata um período hostil da história brasileira, com cenas relativamente pesadas, mobilizou e afetou alunos do $3^{\circ}$ ano do Ensino Médio.

Mas esse resultado não foi imediato, tampouco automático. Embora o audiovisual seja uma linguagem presente na vida de jovens e adolescentes, não é simples incluir o cinema na escola; primeiro, porque ultrapassa a superficialidade da linguagem audiovisual presente no cotidiano dos alunos e, segundo, porque o cinema na escola ainda é associado à ausência de conteúdo ou a uma atividade de lazer. Por isso, "o primeiro antídoto contra [isso] é planejar as atividades em torno do material fílmico a ser incorporado" (NAPOLITANO, 2009, p.23). Tal planejamento envolve a seleção do filme de acordo com os objetivos da aula/disciplina, a identificação de tempo e espaço disponíveis, a caracterização dos alunos; o conhecimento aprofundado da produção cinematográfica pelo professor responsável; a sensibilização dos alunos para a atividade - que pode ocorrer antes mesmo do dia da exibição e discussão do filme; a elaboração de um roteiro de análise com questões, por exemplo.

Além das primeiras impressões identificadas nos alunos durante a exibição (aplausos, atenção, afetos), outros resultados são possíveis - e aqui está nosso maior interesse -, desde que haja, após a exibição, um espaço de reflexão individual, troca entre os pares, discussão e apropriação de novos conteúdos e sentidos. Somente assim será possível superar a superficialidade para alcançar a essência da obra e dar um salto qualitativo de elaboração psíquica e cognitiva, incluindo o incentivo para a formação de leitores. 
Em um desses momentos de reflexão, troca e discussão, uma aluna do $1^{\circ}$ ano do Ensino Médio fez o seguinte comentário sobre o curta Os fantásticos livros voadores do Sr. Morris Lessmore: “Cada livro que estava na biblioteca [cenário do curta] foi escrito por alguém que passou por lá; histórias em preto e branco que ficaram coloridas". Percebe-se nesse relato uma leitura que ultrapassa o enredo, o conteúdo; incorporando as cores, a forma.

O cinema é uma experiência estética e cultural que não se resume à história contada (conteúdo). "Os filmes, como qualquer obra de arte, comunicam e perturbam o espectador mais pela maneira, pela forma como os temas são desenvolvidos, do que pelos temas em si. Por isso, os vários aspectos da linguagem não devem ser menosprezados" (NAPOLITANO, 2009, p.20).

Meses após a exibição e a análise de $O$ menino e o mundo, quando se questionou possíveis contribuições da articulação entre a literatura e o audiovisual no processo ensino-aprendizagem, alguns relatos de alunos foram: "aprendi a dar mais atenção aos detalhes"; "me fez ver o mundo com um outro olhar, com um olhar menos egocêntrico perante as periferias e os obstáculos encontrados". Ou seja, a leitura da imagem em movimento - que não é qualquer imagem em movimento, conforme já discutimos anteriormente - ampliou a leitura de mundo desses alunos.

De acordo com Napolitano (2009), "um filme, como experiência estética e cultural, pode ser visto sob diversos ângulos e chaves de leitura, dialogando, por exemplo, com repertórios culturais e valores dos espectadores" (p.11).

Da mesma forma, a literatura provoca, mobiliza, afeta, humaniza as pessoas. Para Antonio Candido (1988), a literatura "humaniza em sentido profundo porque faz viver" (p.176).

Após a leitura da obra Vidas secas, de Graciliano Ramos (2019[1938]) uma professora de História da Educação Básica, com excelente formação acadêmica, revelou que passou a entender e valorizar a arte após a participação como bolsista da FAPESP ${ }^{9}$

9 A bolsa de Aperfeiçoamento Pedagógico da FAPESP é concedida ao professor da Educação Básica vinculado à pesquisa financiada pela FAPESP na modalidade Ensino Público, cujo objetivo 
em um dos projetos de pesquisa: “[Antes de ler o livro] eu 'sabia, mas não sentia”".

Esse relato demonstra que a inserção do cinema e da literatura na escola também depende da formação qualificada do corpo docente. "Afinal, como promover uma educação do sensível se os professores não estiverem mobilizados e formados a partir de uma perspectiva estética?" (COMBINATO et al., 2018).

Além da recepção estética, a educação da sensibilidade envolve a atividade expressiva (CAMARGO; BULGACOV, 2008). Fundamentadas em Vigotski, essas autoras afirmam que existem a atividade reprodutora e a atividade criadora, e que o processo de aprendizagem não se restringe à atividade reprodutora:

Não sendo reduzida a atividade reprodutora e imitativa, a aprendizagem torna-se uma atividade de enorme complexidade que se vincula à imaginação e à afetividade. A aprendizagem concebida como atividade criadora supõe mudança na proposta pedagógica: mudança de uma prática que nega, reprime, exclui, censura, subordina, marginaliza a imaginação e a vida afetiva dos alunos, para uma prática que transforme a imaginação e a afetividade em ações mobilizadoras da atividade (CAMARGO; BULGACOV, 2008, p.473).

A recepção estética da arte, de certo modo, incentiva a criação. De acordo com Fresquet e Migliorin (2015), "ver cinema, em alguma medida, nos coloca na disposição de criar" (p.15). Isso porque, de acordo com os autores, "ver e fazer são frente e verso de uma mesma práxis" (p.16).

E, assim, a produção - seja ela escrita ou audiovisual - implica a apropriação daquilo que já foi produzido historicamente. A atividade como processo dialético de apropriação - objetivação do gênero humano envolve a objetivação, ou seja, a externalização do sujeito a partir da apropriação daquilo que já foi produzido e acumulado pelo gênero humano.

\footnotetext{
é contribuir com a melhoria do ensino público. Nos projetos de pesquisa e extensão coordenados pelas autoras desse artigo, a participação como bolsista FAPESP envolveu, por exemplo, a participação dos professores em reuniões semanais ou quinzenais com as pesquisadoras responsávéis para estudo, discussão de filmes e textos teóricos e literários, planejamento e avaliação das atividades de pesquisa-ação com alunos, elaboração de relatórios e artigos.
} 
Diante da tarefa proposta a alunos de Ensino Médio para a produção de curtas, vários grupos escolheram desenvolver releituras de obras com as quais tiveram contato na escola, dentre elas, a animação O menino e o mundo, de Alê Abreu (2014) e o poema Ladainha, de Cassiano Ricardo (2014): “As aulas de Língua Portuguesa tiveram grande influência para a construção do nosso audiovisual. Um dos textos escolhidos foi apresentado na aula [...] O grupo se identificou e achou que seria propício colocá-lo no curta, devido à conexão com os dias atuais, onde a máquina tomou o lugar do homem" - relato de aluna do $2^{\circ}$ ano do Ensino Médio, vinculada ao grupo que produziu o curta "Máquina, orai por nós".

Como discutem Berti e Carvalho (2013), com base em Alain Bergala, o cinema promove uma experiência de alteridade: "o cinema permite ser o outro, viver em outro território, flanar por diferentes espaços e tempos” (p.183). Daí a riqueza do cinema - e também da literatura -, tanto no sentido de provocar outras vivências, sentimentos, questionamentos, como no de favorecer o aprendizado de leitura de imagens, textos e mundo.

Segundo relato dos próprios alunos, a participação em projeto de pesquisa e extensão, cujo objeto de estudo foi a arte através do cinema, da literatura e da escrita, aumentou o interesse pela leitura ou intensificou o gosto pela leitura, o que, por sua vez, promoveu o aperfeiçoamento na interpretação de textos: "passei a ler mais, melhorou a minha interpretação" (COMBINATO, 2020).

Após dois anos de trabalho com as mesmas turmas de Ensino Médio (aproximadamente 100 alunos divididos em três turmas) articulando a literatura e o audiovisual no processo ensino-aprendizagem, um levantamento através de questionário não identificado revelou que o interesse/gosto por literatura atingiu $30 \%$ dos alunos e o interesse/gosto por cinema/audiovisual alcançou 53\% do grupo (COMBINATO, 2019).

Apesar de envolver uma pequena amostra, esse dado indica o potencial desse tipo de trabalho na escola para a formação de leitores, especialmente diante do cenário brasileiro. De acordo com a pesquisa Retratos da leitura no Brasil (INSTITUTO PRÓ-LIVRO, 2016), 44\% da população brasileira é composta por não leitores (pessoa que declarou não ter lido nenhum livro nos últimos 3 meses) e o principal gênero de escolha de leitura dos leitores é o religioso. 
No projeto de extensão desenvolvido junto a estudantes da EJA, com idades entre 18 e 57 anos, em 2014, dado o tempo exíguo de cada série escolar e a pouca disponibilidade de tempo dos estudantes, já que a maior parte trabalhava durante o dia e estudava no período noturno, nossa escolha foi apresentar trechos, cenas, de filmes de autor e textos curtos de literatura, como poemas, crônicas, contos e trechos de romances. Coletamos depoimentos de diversos estudantes feitos diretamente para nós, por escrito ou oralmente, assim como declarações orais feitas para alguns de seus professores. Destacamos dois depoimentos, um de uma estudante com mais de 50 anos e outro, de um estudante mais jovem, na faixa de 25 a 30 anos, os quais espontaneamente declararam no questionário final de avaliação do projeto: "Meu neto gosta de leitura e me pediu pra que lesse pra ele este livro [referindo-se a um livro que nós levamos para sala de aula e comentamos, lemos trechos]" e "Até comecei a ler livros e comecei a reservar um tempinho para assistir filme". Além das declarações voluntárias, observamos mudanças de atitudes, como maior frequência às aulas quando íamos à escola para as atividades do projeto, maior interesse nas aulas, alguns alunos começaram a aventar a possibilidade de continuar os estudos.

Em um outro projeto ${ }^{10}$, destacamos as atitudes de alguns estudantes, que após assistirem a um filme na escola, quando o mesmo filme foi exibido em TV aberta, assistiram-no novamente; outros estudantes passaram a pesquisar e a assistir outros filmes de um mesmo cineasta depois de terem assistido na escola e saberem dos meios de produção de um filme, começaram a desenvolver a percepção de cinema de autor; outros ainda ficaram muito surpresos ao conhecerem filmes brasileiros, tais como Narradores de Javé (2003) e Lixo extraordinário (2009), pois até então os únicos nacionais que haviam assistido foram produções do gênero comédia, criados pela Globo Produções; também foi grande a surpresa de diversos alunos ao descobrirem que há animações para adultos, como Mary \& Max (2009).

Um questionamento por parte dos professores que diversas vezes apareceu no desenvolvimento dos projetos que os envolviam, os financiados pela Fapesp, foi como reconhecer um filme como sendo cinema de autor e um texto literário de autores contem- 
porâneos, sem perder de vista que no meio de produções de filmes e literatura de massa poderão aparecer bons cineastas e bons escritores, assim como nem tudo que se produz como cinema de autor ou literatura podem ter qualidade artística. O que é imprescindível é o professor - de qualquer área do conhecimento e não exclusivamente de Língua Portuguesa ou de ciências humanas - se interessar por cinema de autor e literatura, querer sempre aprender a respeito. A partir daí, poderá ler crítica especializada sobre cinema de autor e literatura, tanto em publicações específicas sobre esses assuntos (há diversas online com acesso gratuito), como seções de cultura em jornais e revistas da grande mídia; poderá assistir a programas em TV abertas, em geral as TV públicas e educativas; assistir a entrevistas de cineastas, grandes atores e escritores; poderá acompanhar as indicações e premiações de grandes festivais de cinema e feiras literárias, há diversos festivais de cinema e feiras literárias no Brasil. Esses eventos de cinema e literários têm como jurados especialistas nas áreas, já se tendo, portanto, um filtro das produções. Cabe, aqui, uma restrição ao Oscar - Prêmios da Academia (Academia de Artes e Ciências Cinematográficas), por ser um evento promovido pelos grandes estúdios cinematográficos estadunidenses, cujo objetivo é premiar profissionais da "indústria cinematográfica", em geral, as próprias produções dessa indústria, evento que, até uns dez anos atrás, tinha como jurados apenas profissionais da área ligados às produções comerciais estadunidenses. Não se trata de desconsiderá-lo, obviamente, pois as premiações para filmes estrangeiros e animação costumam ser semelhantes às avaliações de jurados de grandes festivais de cinema de autor, mas olhar com certa reserva para o Oscar poderá ajudar a desenvolver o senso crítico para os elementos de roteiro e estéticos dos filmes.

A história nos mostra que há obras de arte, cujo início foi popular, ou de produções inicialmente malvistas e que, após um certo tempo, são lançadas ao status de arte. É vasto o debate sobre o que é arte, debate do qual dá para extrair algumas condições, as quais têm pesos diferentes, para que uma produção possa ser considerada artística: o reconhecimento pela sociedade, que inclui os canais de divulgação (espaços para publicizar), avaliação de especialistas e aceitação do público. É nesse conjunto de forças, nessa tensão, que uma produção, inicialmente da cultura popular ou mesmo da indústria cultural, pode ser alçada à condição de obra de arte, o que quer dizer que nem todas as obras que hoje conhecemos como arte já nasceram assim. 


\section{CONSIDERAÇÕES FINAIS}

A justificativa de que as produções cinematográficas e literárias de massa são as que os estudantes (mais) apreciam não se mostrou verdadeiro, diante de nossa experiência com projetos de pesquisa e extensão junto aos estudantes de Ensino Médio de escolas públicas. É certo que introduzir na escola literatura contemporânea e, principalmente, cinema de autor é tarefa que demanda estudo pelo professor e tempo para preparação das atividades, considerando ainda que muitos professores, assim como os alunos, são massificados pelas produções da indústria cultural. Então, apesar de serem leitores assíduos e cinéfilos, seus repertórios estão restritos às produções que têm como princípio e direção o retorno financeiro em larga escala.

Ainda considerando nossa experiência com os projetos, parece-nos claro que se trata de apresentar - e insistir com - as produções mais elaboradas, que rompem com as interpretações previsíveis, por isso repetitivas e fáceis. O trabalho com essas produções pode deslocar formas de pensamento tanto de estudantes como de professores. É preciso também um olhar atento, sem pressa, para perceber modificações nas formas de pensar e agir dos estudantes, as quais num primeiro momento poderão parecer pequenas e até insignificantes, mas que ao longo do tempo poderão se mostrar muito significativas. Embora os projetos tenham sido desenvolvidos junto a estudantes jovens e de seus professores, exceto o voltado para o público da EJA, cujas turmas tinham estudantes adultos, o trabalho com cinema de autor e textos de literatura de autores contemporâneos poderá iniciar bem mais cedo, pois há materiais de grande qualidade nessas duas áreas, produzidos para o público infantil e juvenil, que cursam o Ensino Fundamental. 


\section{REFERÊNCIAS}

BERTI, A.; CARVALHO, R. M. O Cine Debate promovendo encontros do cinema com a escola. Pro-Posições, Campinas, v.24, n.3, p.183-199. 2013. Disponível em: http://www.scielo.br/pdf/pp/v24n3/11.pdf Acesso em 30 ago 2018.

BRASIL. Lei n.9.394, de 20 de Dezembro de 1996. Estabelece as diretrizes e bases da educação nacional. Disponível em: http://www.planalto.gov.br/ccivil_03/LEIS/ L9394.htm Acesso em 22 fev 2020.

BRASIL. Lei n.13.006, de 26 de junho de 2014. Estabelece as diretrizes e bases da educação nacional, para obrigar a exibição de filmes de produção nacional nas escolas de educação básica. Disponível em: http://www.planalto.gov.br/ ccivil_03/_Ato2011-2014/2014/Lei/L13006.htm Acesso em 22 fev 2020.

CAMARGO, D.; BULGACOV, Y. L. M. A perspectiva estética e expressiva na escola: articulando conceitos da psicologia sócio-histórica. Psicologia em estudo, v. 13, n. 3, p. 467-475, 2008.

CANDIDO, A. O direito à literatura. In: CANDIDO, A. Vários escritos. 3. ed. São Paulo: Duas cidades, 1988. p. 169-191.

CHAUÍ, M. Convite à filosofia, 13. ed. São Paulo: Ática, 2003.

COMBINATO, D. S.; OLIVEIRA, T. C. S. ; MACEDO, W. P. ; VIEIRA, I. G. ; AUGUSTO, J. M. M. ; RIBEIRO, A. M. L. . Formação docente como condição para o planejamento e desenvolvimento de pesquisa-ação com alunos do Ensino Médio. In: V Congresso Nacional de formação de professores e XIV Congresso Estadual Paulista sobre formação de educadores, 2018, Águas de Lindoia. Inovação e Tradição - preservar e criar na formação docente, 2018.

COMBINATO, D. S. "Nós e os nossos nós: impactos da articulação entre literatura e audiovisual para o processo ensino-aprendizagem no Ensino Médio". Relatório científico. Programa de Melhoria do Ensino Público da Fundação de Amparo à Pesquisa do Estado de São Paulo. Processo n. 2014/50841-4. FAPESP, 2019.

COMBINATO, D. S. “Nós e os nossos nós: impactos da articulação entre literatura e audiovisual para o processo ensino-aprendizagem no Ensino Médio". Relatório 
científico. Programa de Melhoria do Ensino Público da Fundação de Amparo à Pesquisa do Estado de São Paulo. Processo n. 2014/50841-4. FAPESP, 2020. DUARTE, N. As pedagogias do "aprender a aprender" e algumas ilusões da assim chamada sociedade do conhecimento. Revista Brasileira de Educação, n. 18, p.35-40, 2001. Disponível em: http://www.scielo.br/pdf/rbedu/n18/n18a04 Acesso em 05 out 2019.

FRESQUET, A.; MIGLIORIN, C. Da obrigatoriedade do cinema na escola, notas para uma reflexão sobre a Lei 13.006/14. In: FRESQUET, A. Cinema e educação: a Lei 13.006 Reflexões, perspectivas e propostas. Belo Horizonte, MG. Universo Produções, 2015.

FRESQUET, A.; PAES, B. T. A escola e o cinema: algumas reflexões e apreensões frente à Lei 13.006/14. Revista Teias, v. 17, n. 47, 2016: Cinema e Educação em Debate. Disponível em: https://www.e-publicacoes.uerj.br/index.php/revistateias/ article/view/24585/17565 Acesso em 22 fev 2020.

GEADA, E. O cinema espetáculo, Lisboa: Edições 70, 1987.

GHIRALDELO, C. M. A interpretação de filmes cult por jovens habituados a filmes comerciais. In RIBEIRO, J. da S.; VIANA, C. E.; MACIEL, D. (Orgs.) Encontros de Cinema. $4^{a}$ Conferência Internacional de cinema de Viana 2015. Viana do Castelo, Ao Norte (Associação de Produção e Animação Audiovisual), 2016.

GONÇALVES FILHO, A. A. Educação e literatura. 2.ed. Rio de Janeiro: DP\&A, 2002. INSTITUTO PRÓ-LIVRO. Retratos da leitura no Brasil. 4.ed. 2016. Disponível em: http://prolivro.org.br/home/images/2016/Pesquisa_Retratos_da_Leitura_no_ Brasil_-_2015.pdf Acesso em 17 fev. 2020.

LAVAL, C. A escola não é uma empresa: o neoliberalismo em ataque ao ensino público. Trad. Mariana Echalar. São Paulo: Boitempo, 2019.

MINISTÉRIO DA EDUCAÇÃO. INSTITUTO NACIONAL DE ESTUDOS E PESQUISAS EDUCACIONAIS ANÍSIO TEIXEIRA. Censo da Educação Básica 2019. Brasília-DF Inep/MEC, 2020. Disponível em: http://portal.inep.gov.br/documents/186968/0/Notas+Estat\%C3\%ADsticas+-+Censo+da+Educa\%C3\%A7\%C3\%A3o+B\%C3\%A1sica+2019/43bf4c5b-b478-4c5d-ae17-7d55ced4c37d?version=1.0 Acesso em 22 fev 2020. 
MORAES, O., HANNING, R., PARAGUASSU, M. Traço e prosa: entrevistas com ilustradores de livros infantojuvenis. São Paulo: Cosac Naify, 2012.

NAPOLITANO, M. Cinema: experiência cultural e escolar. Secretaria da Educação. Caderno de cinema do professor: dois. São Paulo: FDE, 2009.

PERISSÉ, G. Literatura e educação. Belo Horizonte: Autêntica, 2006.

QUEIRÓS, B. C. Sobre ler, escrever e outros diálogos. Organização de Júlio Abreu. Belo Horizonte: Autêntica, 2012.

ROSENFELD, A. Cinema: arte \& indústria. São Paulo: Perspectiva, 2009[1951].

SARAMAGO, J. Nas suas palavras. Edição e seleção de Fernando Gómez Aguilera. 2.ed. Alfragide, Portugal: Caminho, 2010.

WOOD, J. Como funciona a ficção. Trad. Denise Bottmann. São Paulo: Cosac Naify, 2011. Obras audiovisuais:

A palavra conta, de Duto Sperry, produzido pela Java 2G, com apoio do Instituto C\&A, 2011. 28'37". Disponível em: https://www.youtube.com/watch?v=TlOwKhIma5s Acesso em: 19 jan 2017.

Com amor, Van Gogh, filme de Dorota Kobiela, Hugh Welchman, produzido por Breakthru Productions Trademark Films, 2017.94.

Lixo extraordinário, filme de Lucy Walker, João Jardim e Karen Harley, produzido por Almega Projects, O2 Filmes, 2010. 90'.

Mary \& Max - Uma amizade diferente, filme de Adam Elliot, produzido por Melanie Coombs, 2009. 92'.

Narradores de Javé, filme de Eliane Caffé, produzido por Bananeira Filmes, Gullane Filmes, Laterit Productions, Riofilme, 2003, 100'.

O menino e o mundo, de Alê Abreu, produzido por Filme de Papel e Espaço Filmes, 2014. 80'.

Olga, filme de Jayme Monjardim, produzido por Globo Filmes e Lumière Pictures, 2004. 141'.

Os fantásticos livros voadores do Sr. Morris Lessmore, filme de William Joyce e Brandon Oldenburg, produzido por Moonbot Studios, 2011. 15’07”. Disponível em: https://www.youtube.com/watch?v=wDkfhwRlcZw Acesso em: 09 nov 2017. 
Paris, je t'aime, Faubourg Saint Denis, filme de Tom Tykwer, produção de Imagem Filmes, 2006. 7'13". Disponível em: https://www.youtube.com/watch?v=CNOxsLK8KUc Acesso em 08 fev 2017.

Obras literárias:

FUNDAÇÃO CULTURAL CASSIANO RICARDO. Cassiano Ricardo 120 anos. São José dos Campos, 2014.

RAMOS, G. Vidas secas. 140.ed. Rio de Janeiro/São Paulo: Record, 2019[1938]. 